\title{
Distribution and Regulation of the Candidate Prohormone Processing Enzymes SPC2 and SPC3 in Adult Rat Brain
}

\author{
N. P. BIRCH* , D. J. HAKEST, J. E. DIXON† and E. MEZEY‡
}

*Section on Cellular Neurobiology, Laboratory of Developmental Neurobiology, National Institute of Child Health and Human Development, National Institutes of Health, Bethesda, MD 20892, USA and School of Biological Sciences, University of Auckland, Private Bag 92019, Auckland, New Zealand, tDepartment of Biological Chemistry, University of Michigan Medical School, Ann Arbor, Michigan 48109-0606, USA, ¥Laboratory of Cell Biology, National Institute of Mental Health, National Institutes of Health, Bethesda, MD 20892, USA

Abstract-A number of candidate mammalian prohormone processing enzymes related to the yeast Kex2 endoprotease have been cloned and demonstrated to cleave several prohormone precursors at single, pairs and tetra basic amino acid processing sites. We have mapped the distribution of the mRNAs encoding two of these endoproteases in adult rat brain. SPC3 message levels showed a more restricted distribution and generally lower levels than SPC2 transcripts. The highest levels of SPC2 mRNA were found in the pyramidal cells of the hippocampus, several thalamic nuclei, the habenula and selected nuclei in the hypothalamus. SPC3 mRNA was most abundant in dentate gyrus granule cells, the habenula and selected hypothalamic nuclei. In the hypothalamus overlapping and unique distributions of the two transcripts were seen in the paraventricular nucleus with SPC3 mRNA predominantly expressed in lateral magnocellular cells. Both SPC2 and SPC3 mRNA were upregulated in the paraventricular and supraoptic hypothalamic nuclei following chronic salt loading. Combined immunocytochemistry/in situ hybridization histochemistry demonstrated that SPC2 and SPC3 transcripts were both expressed in the vasopressinergic subpopulation of magnocellular neurons in the supraoptic nucleus. SPC3 mRNA, but not SPC2 transcripts, also colocalized with immunoreactive vasopressin-associated neurophysin in the suprachiasmatic nucleus. These results remain consistent with roles for SPC2 and SPC3 in the biosynthesis of neuropeptides and for a specific role for SPC3 in the processing of provasopressin. Increased levels of SPC2 and SPC3 transcripts following a chronic osmotic stimulus suggests these proteases are coregulated with prohormone substrates and may be useful as an indicator of peptidergic activity.

Date received 20 April 1994

Date accepted 2 May 1994

Correspondence to: Nigel P. Birch, School of Biological Sciences, University of Auckland, Private Bag 92019, Auckland, New Zealand.
Introduction

Most biologically active peptides are synthesized as part of larger inactive precursors. These proproteins undergo a series of post-translational 
modifications which ultimately result in the synthesis of biologically active peptides. Post-translational modifications include selective proteolysis by endo- and exopeptidases, amidation, acetylation, phosphorylation and sulphation. ${ }^{1,2}$ Early biosynthesis studies of the insulin precursor identified pairs of basic residues as a major processing site during the biosynthesis of mature insulin. ${ }^{3}$ Selective proteolysis at dibasic amino acids has since been identified as a common, although not exclusive, step in the biosynthesis of many hormones and neuropeptides. ${ }^{1,2.4 .5}$

While evidence to support the existence of paired basic residue-specific endoproteases has accumulated over the last 20 years, the identification, purification and characterization of such enzymes in endocrine and neuroendocrine tissues has proved difficult. Aspartic, cysteine, serine and metallo proteinases have been proposed as paired basic residuespecific endoproteases involved in the maturation of several different prohormones. ${ }^{1,2}$ Recently a new family of serine endoproteases likely to be involved in proprotein maturation has been identified following studies of yeast by Jeremy Thorner and his colleagues. Utilizing Saccharomyces cerevisiae mutants which were unable to process yeast proproteins at paired basic residue cleavage sites, these researchers identified a gene, $K E X 2$, responsible for maturation of these precursors. The $K E X 2$ gene product encoded a $90 \mathrm{kDa}$ protein with considerable similarity to the bacterial subtilisin serine protease family. ${ }^{6}$ Coexpression of the $K E X 2$ gene with mammalian prohormone precursors in eukaryotic cell lines unable to process these precursors, resulted in hybrid cell lines capable of processing at pairs of basic amino acids. ${ }^{7}$ These data suggested that a mammalian homologue of the $K E X 2$ gene may be involved in eukaryotic proprotein maturation.

Once the $K E X 2$ gene had been isolated and sequenced, ${ }^{8.9}$ a search of the protein database identified a partial sequence of a related human protein called furin. ${ }^{10,11}$ Characterization of a second mammalian Kex 2 homologue was reported in 1990 by the laboratories of Steiner ${ }^{12}$ and Seidah. ${ }^{13}$ We subsequently reported the cloning of two full length cDNAs from a rat insulinoma cell line which encoded homologues of the yeast Kex2 protease. $^{14}$ One cDNA was identified as the rat equivalent of the human insulinoma $\mathrm{PC} 2$ protein while the second clone, named BDP, coded for a 752 amino acid protein with considerable amino acid similarity to Kex 2 and furin, particularly in the enzyme active site regions. A uniform terminology to uniquely identify the 5 current mammalian members of this endoprotease family ${ }^{11,12,14-19}$ was recently proposed by Steiner and his colleagues ${ }^{20}$ and will be used in this paper. Therefore, the enzymes characterized in this study will be known as SPC2 (previously called PC2 and RPC2) and SPC3 (previously called PC3, PCl and BDP).

In our previous paper, ${ }^{14}$ along with nucleic acid sequence data and Northern blot analyses, we reported the distribution of SPC2 and SPC3 messenger RNAs in the rat pituitary gland and at a single anatomical level in adult rat brain. Extensive analyses of expression in endocrine and non-endocrine cell lines and other tissues supported a restricted distribution of SPC2 and SPC3 transcripts to endocrine and neuroendocrine cell types..$^{13,15,21}$ In the present study we have completed a detailed in situ hybridization analysis of the distribution of SPC2 and SPC 3 transcripts in adult rat brain and looked at the regulation of message levels following a hyperosmotic stimulus. Using combined in situ hybridization and immunocytochemistry we have looked at the distribution of enzyme transcripts in the vasopressin-expressing neurons of the supraoptic and suprachiasmatic nuclei.

\section{Materials and methods}

Oligonucleotide probes and radiolabelling procedure

Two synthetic 48 mer oligonucleotides specific for either SPC2 or SPC3 were synthesized using phosphoramide chemistries by Genosys Biotechnologies (The Woodlands, TX, USA). The sequences of the oligonucleotides were complementary to bases 1366-1413 and 1998-2045 of rat SPC2 and 12341281 and $1744-1791$ of rat SPC3. ${ }^{14}$ A 48 mer rat vasopressin-specific oligonucleotide probe was complementary to bases $1887-1934 . .^{22}$ The oligonucleotides were purified by polyacrylamide gel electrophoresis and labelled at the $3^{\prime}$ terminus using terminal deoxynucleotidyl transferase (Boehringer Mannheim Biochemicals, Indianapolis, IN, USA) and $\left[\alpha-{ }^{35} \mathrm{~S}\right]$ deoxyadenosinetriphosphate (New Eng- 
land Nuclear, Boston, MA, USA; > $1000 \mathrm{Ci} / \mathrm{mmol}$ ) to specific activities ranging between $1.3-3.4 \times 10^{9}$ $\mathrm{dpm} / \mu \mathrm{g}$. Pairs of probes specific for each enzyme transcript were used at a final concentration of $1.3 \times 10^{5} \mathrm{dpm} /$ section.

\section{Animal protocols and tissue sectioning}

Male Sprague-Dawley rats $(200-300 \mathrm{~g})$ were used in all studies and were treated in accordance with the National Institutes of Health (NIH) Guide for the Care and Use of Laboratory Animals. Rats were kept under controlled temperature and lighting conditions with free access to food and water before use. In the chronic salt loading experiments, the experimental group $(n=4)$ animals were given $2 \%$ saline for 7 days while the control group $(n=4)$ continued with free access to water. Rats used for in situ hybridization/immunocytochemistry studies were injected with colchicine one day prior to sacrificc. Rats were sacrificed by decapitation and the brains removed, frozen on dry ice and stored at $-70^{\circ} \mathrm{C}$ until sectioning. Coronal sections $(12 \mu \mathrm{m})$ were cut at $120 \mu \mathrm{m}$ intervals for mapping studies and thaw mounted on to twice gelatin-coated glass slides. Consecutive $12 \mu$ m sections were cut through the hypothalamus for analyses of message levels following chronic salt loading and for combined in situ hybridization/immunocytochemistry. All sections were stored at $-70^{\circ} \mathrm{C}$ until use.

\section{Hybridization and immunocytochemistry procedures}

In situ hybridization was performed essentially as described previously. ${ }^{23}$ Sections were fixed for 5 min with $4 \%$ formaldehyde in phosphate buffered saline, pH 7.4 (PBS) and then treated with $0.25 \%$ acetic anhydride in $0.1 \mathrm{M}$ triethanolamine $/ 0.9 \%$ $\mathrm{NaCl}, \mathrm{pH} 8.0$ for 10 min. Following dehydration in increasing concentrations of ethanol the sections were delipidated in chloroform and air dried. Hybridization reactions were performed in $50 \%$ formamide, $4 \times \mathrm{SSC}(1 \times \mathrm{SSC}=0.15 \mathrm{M} \mathrm{NaCl} / 0.15$ $\mathrm{M}$ sodium citrate, $\mathrm{pH} 7.2$ ), $0.02 \%$ Ficoll, $0.02 \%$ polyvinylpyrrolidone, $0.02 \%$ bovine serum albu$\min , 500 \mu \mathrm{g} / \mathrm{ml}$ sheared single stranded salmon sperm DNA, $250 \mu \mathrm{g} / \mathrm{ml}$ yeast tRNA, $10 \%$ dextran sulphate and $50 \mathrm{mM}$ dithiothreitol for $16 \mathrm{~h}$ at $37^{\circ} \mathrm{C}$.
Slides were rinsed in $1 \times$ SSC and washed for four 15 -min intervals in $2 \times \mathrm{SSC} / 50 \%$ formamide at $40^{\circ} \mathrm{C}$, followed by two $60-\mathrm{min}$ rinses in $1 \times \mathrm{SSC}$ at $25 \mathrm{C}$. The sections were then briefly rinsed in distilled water, $70 \%$ ethanol and $95 \%$ ethanol and then air dried for autoradiography. Controls and experimental samples from rats following chronic salt loading were all hybridized in a single experiment.

For combined immunocytochemistry/in situ hybridization experiments, rats were anesthesized with ether and perfused with $300 \mathrm{ml}$ of $4 \%$ paraformaldehyde and $1 \%$ picric acid in $0.1 \mathrm{M}$ sodium phosphate buffer, $\mathrm{pH}$ 7.4. Brains were quickly removed, postfixed in the same fixative for $2 \mathrm{~h}$ at $4 \mathrm{C}$ and soaked in a cryoprotectant solution $(20 \%$ sucrose and $3 \%$ polyethylene glycol [400 MW] in physiological saline) overnight. Brains were stored in isopentane at $-20 \mathrm{C} .10 \mu \mathrm{m}$ thick coronal sections were cut in a cryostat (Reichert-Jung Frigocut $2800 \mathrm{E}$ ) and stored at $-70 \mathrm{C}$ until they were stained. Sections were immunostained using the PS41 antibody $^{24}$ at a $1: 200$ dilution, transferred into PBS and then processed for in-situ hybridization as described above.

Slides were exposed to Hyperfilm- $\beta$-Inax (Amersham, Arlington Heights, IL, USA) for $11 \mathrm{~d}$ at room temperature and developed according to the manufacturers recommendations. Positive images of whole brain sections were printed from the film. Slides were subsequently dipped in NTB3 nuclear track emulsion (Kodak, $1: 1$ dilution in $\mathrm{H}_{2} \mathrm{O}$ ) and stored dessicated at $4 \mathrm{C}$ for $28 \mathrm{~d}$ before development using Kodak Dektol at $15 \mathrm{C}$. Dipped sections hybridized with the vasopressin-specific oligonucleotide probe were exposed for $3 \mathrm{~d}$. Cells were counterstained with Toluidine blue $(0.2 \%)$ and grain distribution determined under both bright-field and dark-field illumination.

Quantification of SPC2 and SPC $3 \mathrm{mRNA}$ following in situ hybridization

Changes in SPC2 and SPC3 message levels in hypothalamic brain sections from control and chronically salt loaded rats were determined by image analysis of the autoradiograph. All sections were exposed to a single sheet of Hyperfilm- $\beta$-max and digitized in one session. Image 1.31 software (W.S. 
Rasband, Research Services Branch, NIMH, NIH, MD, USA) was run on a Macintosh II computer with a QuickCapture frame grabber card (DT2255$60 \mathrm{~Hz}$, Data Translation Inc., Marlboro, MA, USA) in conjunction with a Sierra Scientific MS 4030 solid state video camera (Sunnyvale, CA, USA), $55 \mathrm{~mm}$ MicroNikkor lens with extension tubes and a variable intensity light box (Northern Lights, Precision 890, Imaging Research Inc., Toronto, Ontario, Canada). Images were digitized to $a 40 \times 480$ matrix with light transmittance coded in 256 equal gray levels. $6-8$ anatomically matched sections per animal from brains of 4 control or saltloaded rats were digitized. Average densities of the paraventricular nuclei and supraoptic nuclei were determined following delineation of each nucleus by cursor control. The mean values for each nucleus in each animal were determined and statistically analysed using an unpaired two tailed Student's ttest.

\section{Results}

The high degree of similarity between SPC2 and SPC3 indicated to us that oligonucleotides synthesized to regions most divergent between the two clones should provide unique specificities to allow an investigation of the distribution of mRNA for each endoprotease in rat brain. We used two oligonucleotide probes for each enzyme transcript to enhance the signal to noise ratio for in situ hybridization. The specificity of the oligonucleotide probes has been demonstrated in earlier work. ${ }^{14,25}$ Each of the two probes gave an identical pattern of labclling when used separately in trial sections through the brain which supported their recognition of specific mRNAs. No transcripts were apparent in any of the known fibre tracts. Northern blot analyses of rat pituitary intermediate lobe RNA showed hybridization to two major RNA species with either the SPC2 or SPC3-specific probes. The sizes of the SPC2 mRNA species $(\sim 4.8 \mathrm{kB}$ and $\sim 2.8 \mathrm{kB})$ are identical to those previously reported by ourselves ${ }^{14}$ and Steiner's group ${ }^{12}$ who used longer cDNA probes. The two major SPC 3 mRNA species $(\sim 5.0$ and $\sim 3.0 \mathrm{kB}$ ) identified with the pooled SPC3specific oligonucleotide probes are likely to represent the $\sim 5.0 \mathrm{kB}$ and $\sim 3.0 \mathrm{kB}$ transcripts we have cloned from a rat pancreatic cell line cDNA library. ${ }^{14}$ Both cDNAs encoded the same protein but utilized different polyadenylation sites.

Both SPC2 and SPC3 transcripts were found in brain. Generally, SPC2 transcripts were more abundant and widespread than SPC3 transcripts. A detailed analysis of the major brain structures and nuclei which contain SPC2 and SPC3 mRNA is shown in Figures 1,2 and 3. In the telencephalon SPC2 transcripts were relatively abundant in the cortex (Fig. 1A-D). Microscopic examination of cortical regions showed cells with varying labelling intensities with a region, tentatively identified as layer 3, exhibiting very low levels of expression PC2 transcripts (Fig. 3A). The piriform cortex showed strong labelling. The bed nucleus accessory of the olfactory tract had moderate levels of SPC2 mRNA while the septum was strongly labelled (Fig. 1A). In the basal ganglia SPC2 transcripts were very abundant in the caudate putamen but absent in the globus pallidus (Fig. 1A, B, Fig. 3B). SPC2 transcripts were expressed in the hippocampal formation (Fig. 1B, C). Pyramidal cells were intensely labelled in all 4 fields of Ammons horn. Dentate granule cells also labelled but showed lower levels of SPC2 transcripts (Fig. 3D, E). The amygdala expressed SPC2 mRNA (Fig. 1C) with the medial amygdaloid nucleus, both dorsal and ventral, particularly prominent.

Oligonucleotide probes specific for SPC3 transcripts indicated very low levels of cortical labelling (Fig. 2A, B). The hippocampus strongly expressed SPC3 transcripts but in contrast to SPC2 transcripts, labelling was more intense in the granule cells of the dentate gyrus with lower levels of transcripts in the pyramidal cell layer (Fig. 2A, B). The basolateral amygdaloid nucleus showed low levels of SPC2-specific labelling. No specific labelling was seen in the striatum.

Within the diencephalon, both the supraoptic and paraventricular hypothalamic nuclei had high levels of SPC2 messenger RNA. The suprachiasmatic nucleus and scattered cells within the lateral hypothalamic area (Fig. 3C) were strongly labelled. Slightly lower levels of transcripts were seen in the retrochiasmatic, supraoptic and ventromedial, dorsal and dorsal medial hypothalamic nuclei. High levels of SPC2 transcripts were found in the thalamus (Fig. 1B, C, Fig 3D). Particularly 

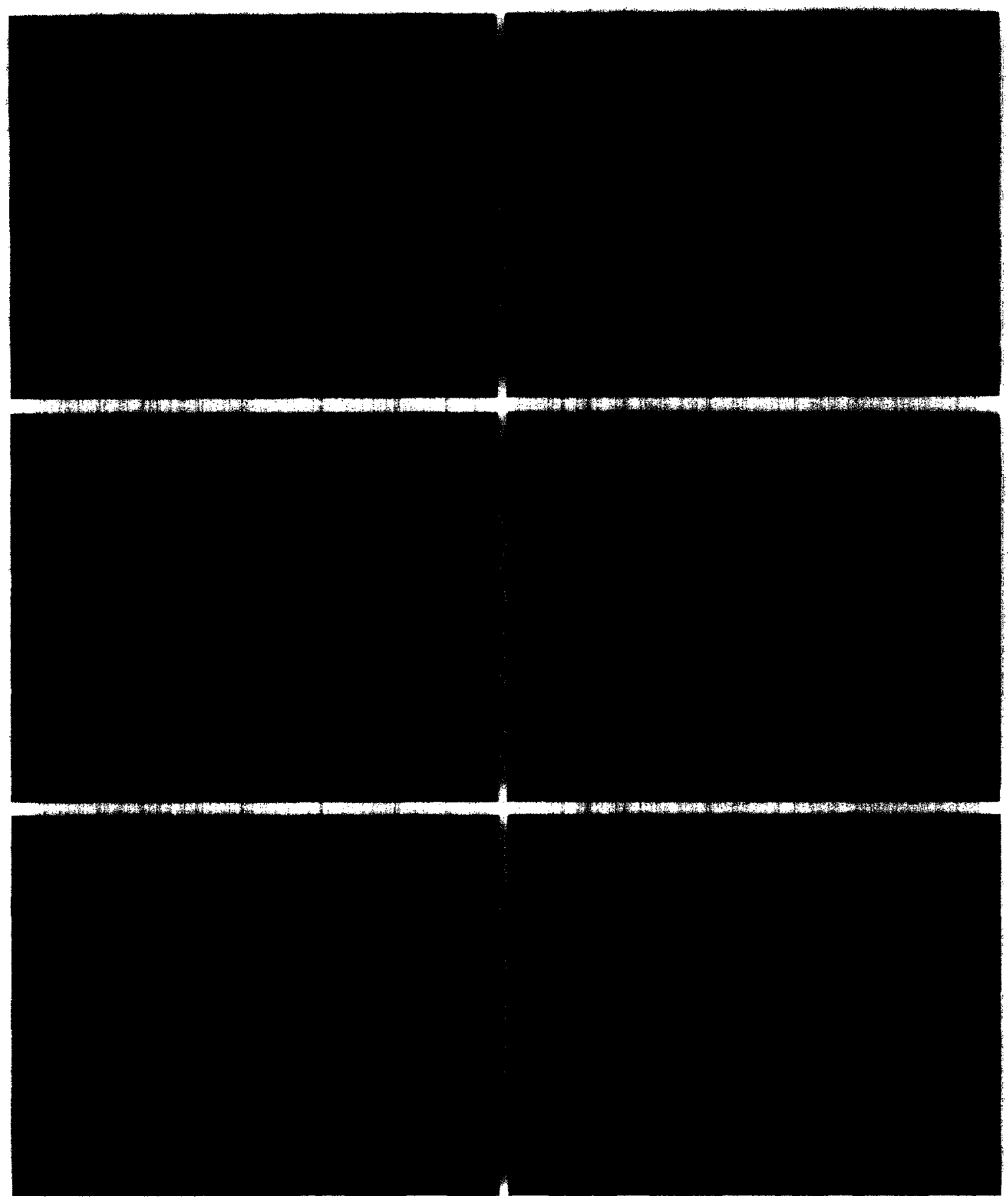

Fig. 1 Labelling pattern of SPC2-specific oligonucleotide probes in adult rat brain. Coronal sections were cut rostral (A) to caudal (F) and hybridized to SPC2-specific oligonucleotides. $S=$ septum: $C=$ caudate putamen; $\mathrm{Hi}=$ hippocampus; $h=$ habenula; $\mathrm{A}=$ amygdala; $\mathrm{Ht}$ - hypothalamus; $\mathrm{Ci}=$ inferior colliculus; $\mathrm{R}=$ raphe (dorsal) nucleus; $\mathrm{IP}=$ interpeduncular nucleus; $\mathrm{LC}=$ locus coeruleus; $X I I=$ motor nucleus of the 12 th hypoglossal nerve; $\mathrm{O}=$ inferior olive. Brain sections shown at $6.5 \times$ magnification. 

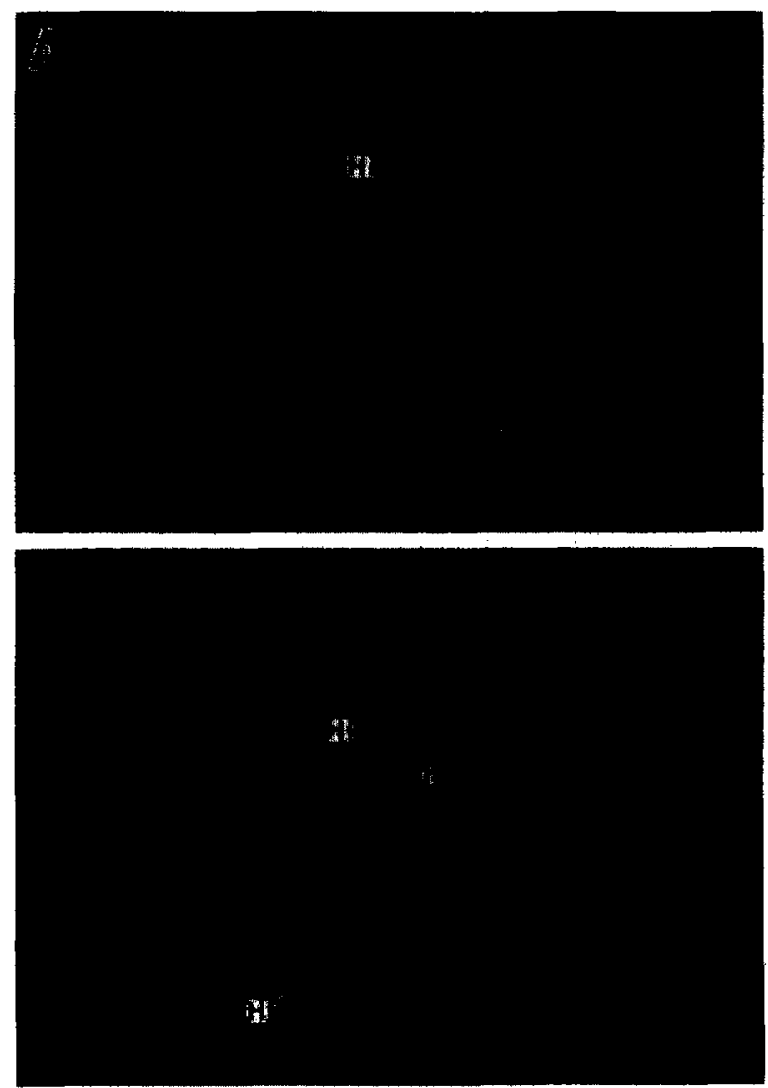

Fig. 2 Labelling pattern of PC3-specific oligonucleotide probes in adult rat brain. Coronal sections were cut rostral (A) to caudal (B) and hybridized to PC3-specific oligonucleotides. $\mathrm{Hi}=$ hippocampus; $\mathrm{P}=$ paraventricular nucleus; So $=$ supraoptic nucleus; $\mathrm{h}=$ habenula; $\mathrm{Ht}=$ posterior hypothalamus. Brain sections shown at $6.75 \times$ magnification

intense labelling was seen in ventrolateral, paraventricular thalamic (anterior), anterodorsal, rhomboid and reuniens thalamic nuclei. The medial habenula was also strongly labelled with the SPC2specific oligonucleotide probes (Fig. 1C). Hybridization with the SPC3-specific probes showed high levels of transcripts were expressed in the paraventricular and supraoptic nuclei (Fig. 2A). The suprachiasmatic and periventricular preoptic hypothalamic nuclei were also labelled, with silver grains over the suprachiasmatic nucleus distributed more parallel to the third ventricle in contrast with the 'tear drop' distribution of SPC2 transcripts. Scattered cells within the periventricular, lateral and posterior hypothalamic nuclei were intensely labelled with the SPC3-specific oligonucleotide probes (Fig. 2B). Low levels of SPC3 transcripts were seen in the arcuate nucleus. Moderate levels of of SPC3-specific labelling were found in the lateral posterior thalamic nucleus and very low levels in the paraventricular and rhomboid thalamic nuclei. The parafascicular thalamic nucleus was labelled only with the SPC3-specific oligonucleotide probes. The lateral habenula showed relatively strong labelling for SPC3 transcripts (Fig. 2B) and the limbic cortex also expressed SPC3 mRNA.

In the mesencephalon moderate levels of SPC2 transcripts were expressed in many nuclei, including the inferior and superior colliculus, pontine reticular formation, central gray, dorsal raphe nucleus and interpeduncular nucleus (Fig. 1D). SPC3 transcripts were generally expressed at low levels in the mesencephalon. Relatively high levels of SPC3 transcripts were expressed in the Edinger-Westphal nucleus (oculomotor nucleus), which is the only motor nucleus that is unaffected in amyotrophic lateral schlerosis. All affected motor nuclei expressed SPC2 mRNA. In the pons, moderate levels of SPC2 transcripts were seen in the locus ceruleus (Fig. 1E), dorsal cochlear nucleus and dorsal tegmental nucleus. Moderate levels of SPC2-specific labelling was detected in the cerebellum (Fig. 1E, F). Labelling was principally over purkinje cells with scattered cells in the granule layer labelled to a similar intensity. No labelling was seen in the molecular layer. SPC3-specific labelling in the cerebellum was mainly over purkinje cells with very little specific labelling of the granule cell layer and no labelling of the molecular layer. In the medulla oblongata SPC2 transcripts were particularly prominent in the inferior olive and the motor nucleus of the 12th hippoglossal nerve (Fig. 1F). Labelling was also found over the nucleus of the solitary tract, dorsal vagal nucleus, nucleus of the trigeminal tract, the reticular formation, area prostrema, superior vestibular nucleus, facial motor nucleus, the nucleus raphe magnus and pallidus, the gigantocellular reticular nucleus, and the prepositus hypoglossal nucleus. Of these nuclei, only the prepositus hypoglossal nucleus labelled with the SPC3specific oligonuclcotide probes. Spinal cord motor and sensory neurons were labelled with the SPC2specific probes and the intermediolateral neurons (vegetative) expressed SPC3 transcripts.

The distribution and regulation of SPC2 and SPC3 transcripts were further analysed in the hypo- 


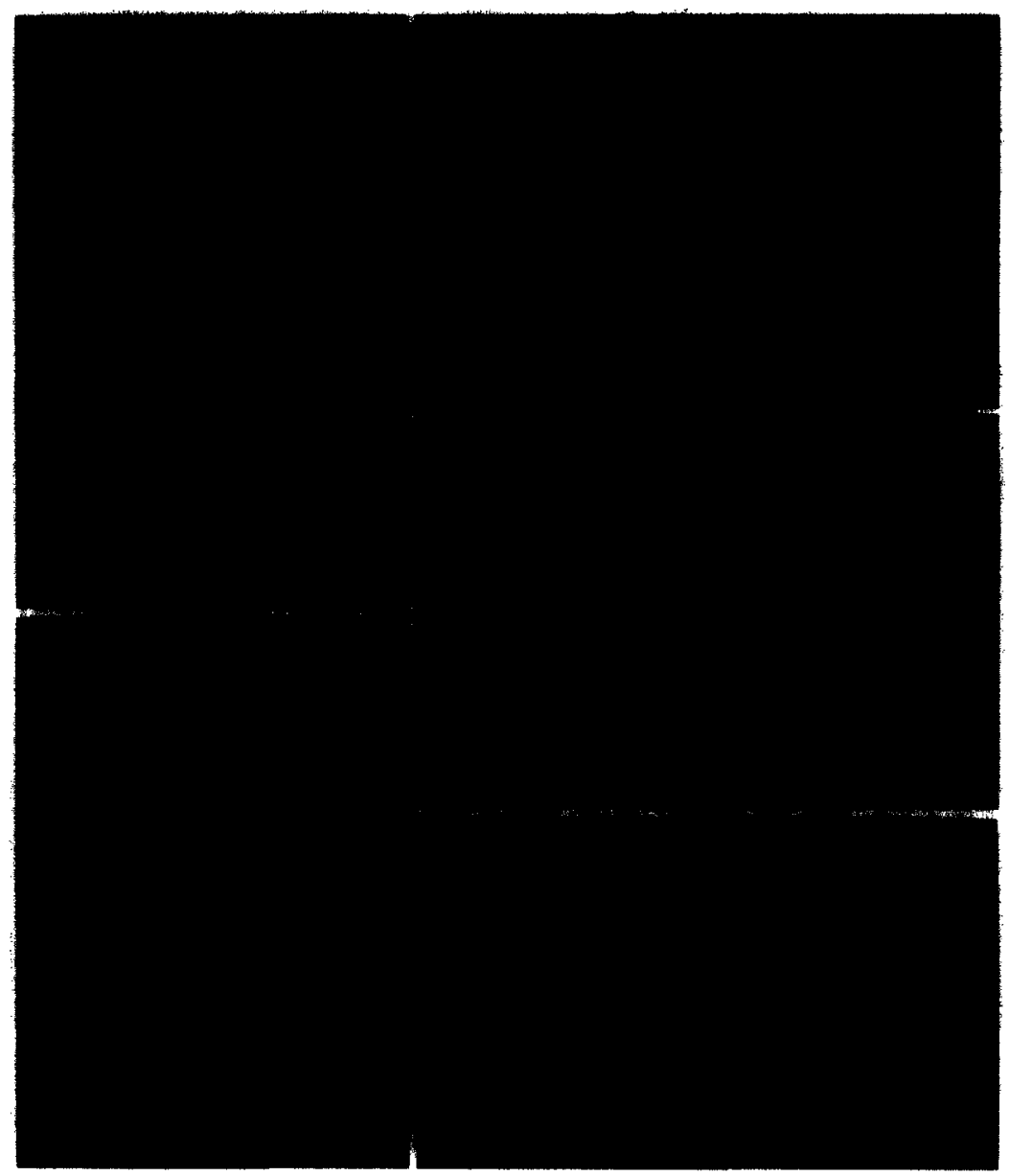

Fig. 3 Dark field photomicrographs of SPC2-specific oligonucleotide labelling in adult rat brain sections. (A) Cortex with unlabelled fibre tracts of the corpus callosum. (B) Striatum showing moderate labelling of the caudate putamen (CP) and no labelling in the globus pallidus (GP). (C) Hypothalamus showing intense labelling of the suprachiasmatic nucleus (SCN) as well as moderate labelling in the anterior hypothalamus. III $v=$ third ventricle; $\mathrm{OC}=$ optic chiasm. (D) Strong labelling of various thalamic nuclci and hippocampus. (E) Intense labelling of hippocampal pyramidal cells and lower levels of labelling of dentate gyrus granule cells. Bar, $200 \mu \mathrm{m}$.

thalamic paraventricular and supraoptic nuclei. As has been shown by many investigators, high levels of vasopressin mRNA were localized to the lateral magnocellular neurons of the hypothalamus. The distribution of SPC 3 transcripts suggested that the enzyme was also predominantly localized to these lateral magnocellular neurons (Fig. 4C). SPC2 showed a more uniform distribution across both the magnocellular and parvocellular cell populations of the paraventricular nucleus (Fig. 4E). Following prolonged hyperosmotic stimulation, levels of SPC2 and SPC3 transcripts increased in both the paraventricular and supraoptic nucleus. SPC 3 transcripts remained predominantly over the lateral magnocellular nerve cells in the paraventricular nucleus (Fig. 4D). The increase in SPC2 message levels was generally spread across the whole nucleus with scattered cells throughout the nucleus exhibiting very high grain densities (Fig. 4F). The relative changes in message levels for SPC2 and SPC3 in the paraventricular and supraoptic nuclei were determined by quantitation of densitometric images on film (Fig. 5). Levels of both enzyme transcripts showed statistically significant increases following ingestion of $2 \%$ saline by rats for 7 days. Levels of SPC3 transcripts were also markedly stimulated in the subfornical organ following salt loading (Fig. $6 \mathrm{~A}, \mathrm{~B})$. 
A

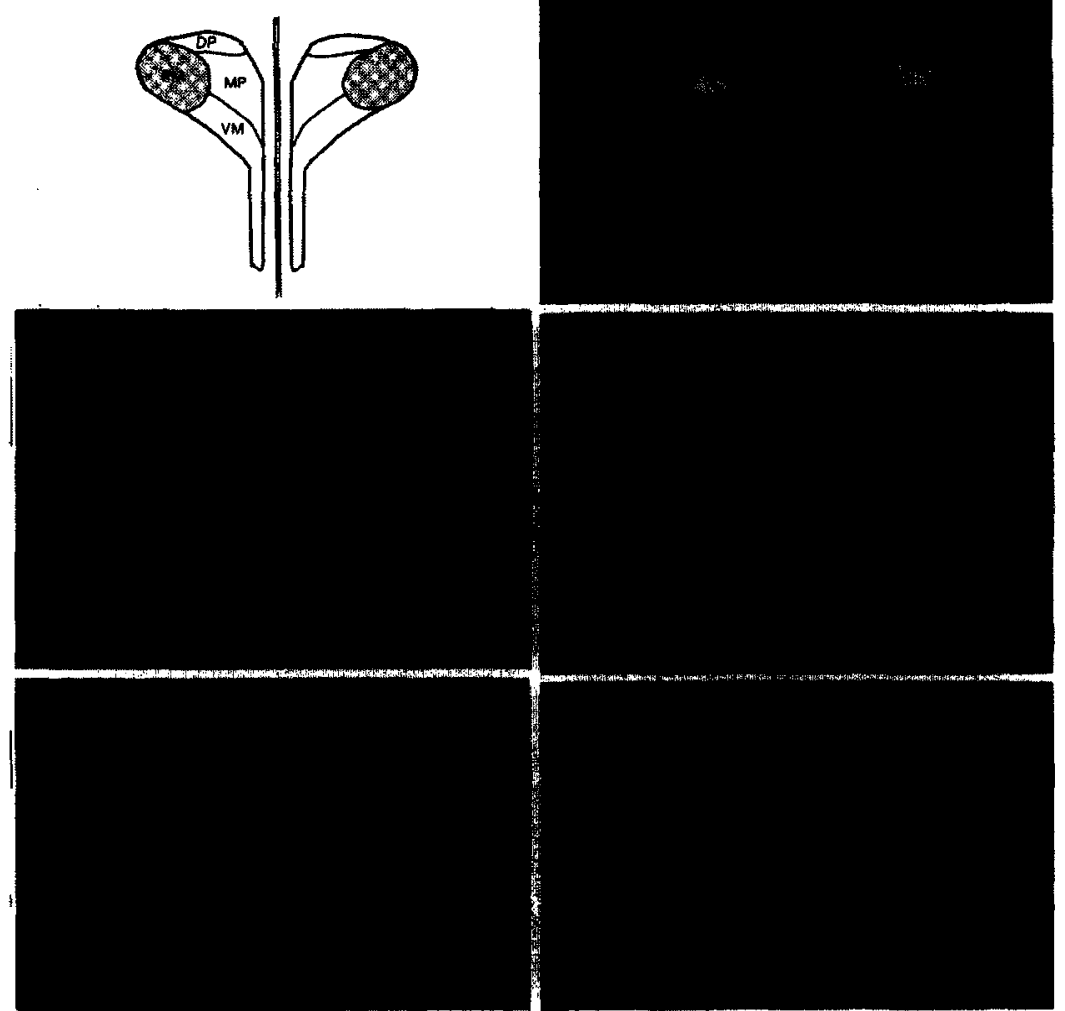

Fig. 4 Dark field photomicrographs of vasopressin-, SPC2- and SPC3-specific oligonucleotide labelling of the paraventricular nucleus following a chronic hyperosmotic stimulus. (A) The major divisions of the paraventricular nucleus. PM = paraventricular lateral magnocellular; $\mathrm{DP}=$ dorsomedial parvocellular; $\mathrm{MP}=$ medial parvocellular; $\mathrm{VM}=$ ventral magnocellular. (B) Intense labelling of magnocellular and accessory parvocellular cells with a vasopressin-specific oligonucleotide probe. (C), (D): SPC3specific labelling in control (C) and following ingestion of $2 \%$ saline for 7 days (D). (E). (F): SPC2-specific labelling in control (E) and following ingestion of $2 \%$ saline for 7 days (F). Bar, $200 \mu \mathrm{m}$.

The major peptidergic phenotype of the SPC2and SPC3-expressing cells of the supraoptic nucleus was determined by combined in situ hybridization/immunocytochemistry. Both SPC2 and SPC3 mRNAs were localized to the vasopressinexpressing subpopulation of magnocellular neurons with no detectable expression in oxytocinexpressing cells (Fig. 7C, D and Fig. 8A, B). Consistent with this result was the lack of both SPC2 and SPC3 transcripts in the islands between the vasopressin-associated neurophysin immunoreactive cells (Fig. 7C, D and Fig. 8A, B) which are known to express oxytocin. More dorsally located magnocellular cells that are most likely to correspond to the oxytocin-expressing subpopulation also failed to show significant labelling with both the SPC2- and SPC3-specific oligo- nucleotide probes (data not shown). In the suprachiasmatic nucleus, SPC3 transcripts were also localized to vasopressin-expressing cells (Fig. 7A, B). No SPC2 mRNA was detected in the vasopressinergic population (data not shown).

\section{Discussion}

In this study we have mapped the distribution of messenger RNAs encoding two candidate prohormone/proneuropcptide processing enzymes in adult rat brain, determined their regulation following a chronic osmotic stimulus and examined their colocalization with vasopressin-expressing cells in the hypothalamus. Both SPC2 and SPC3 transcripts were expressed in adult rat brain. SPC3 


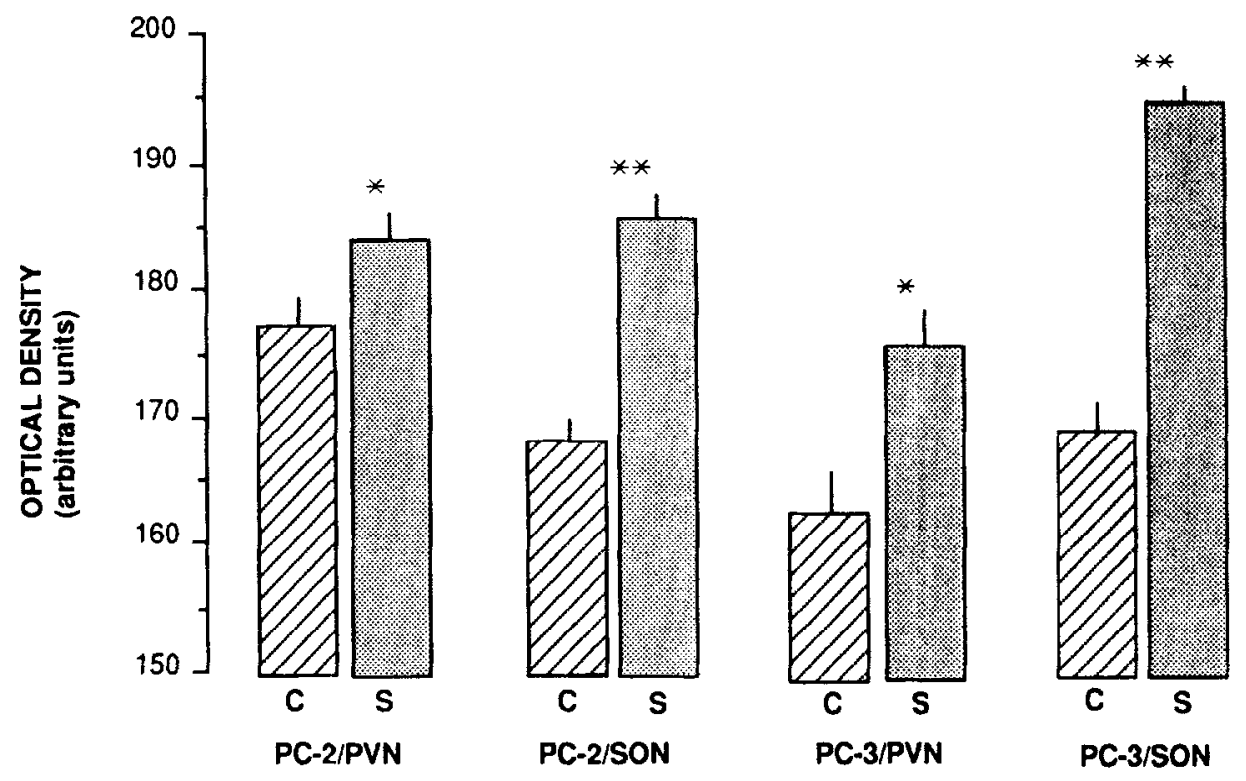

Fig. 5 Densitometric analysis of SPC2 and SPC3 mRNA expression in the paraventricular nucleus of control and hyperosmotic rats. Densitometric measurements of the paraventricular nucleus (PVN) and supraoptic nucleus (SON) in control animals (C) and animals that had ingested $2 \%$ saline for 7 days (S). Each bar shows the mean values \pm SEM and represents digitized images from 6-8 anatomically matched sections per animal and a total of 4 animals for each treatment. Statistically significant differences were determined using an unpaired two-tailed Student's t-test comparing control and experimental values for each nucleus and enzymespecific oligonucleotide probe. ${ }^{*} \mathrm{P} \leqslant 0.05,{ }^{* *} \mathrm{P} \leqslant 0.0001$.

messenger RNA had a more restricted distribution and was expressed in most regions at lower levels than SPC2 transcripts, in general agreement with the mRNA distribution of these endoproteases in mouse brain ${ }^{15}$ and a detailed analysis in rat brain ${ }^{26}$ which has been published since completion of our own studies. Labelling for both SPC2 and SPC3 transcripts was over neuronal cells suggesting that expression of these enzymes was restricted to neuronal tissue. However, we cannot exclude low levels of expression in non-neuronal cells. The exopeptidase carboxypeptidase $\mathrm{H}$, which plays an important role in the biosynthesis of neuroendocrine peptides, has been localized to ependyma ${ }^{23}$ and glial cells $\mathrm{s}^{27.28}$ and these non-neuronal cell types have also been reported to express neuropeptides. ${ }^{29-32}$ However, in the case of proenkephalin there is little processing of this multi-valent precursor to mature peptides ${ }^{33.34}$ suggesting that paired basic residuespecific endoproteases are absent or unable to function in astrocytes.

Considerable evidence from transfection studies has accumulated to support a role for Kex2-related proteases in the biosynthesis of hormones. ${ }^{18,35.36}$ Detailed analyses of proopiomelanocortin pro- cessing has recently been reported by two groups who used the recombinant vaccinia virus expression system to coexpress SPC2 and/or SPC3 with proopiomelanocortin in a 'maturation-deficient' monkey kidney cell line. ${ }^{37,38}$ Both groups observed processing of this multivalent precursor at pairs of basic amino acids which bracket several biologically active peptides and at the tetra basic residue-processing site within ACTH to release $\alpha$ MSH. The localization of SPC2 and SPC3 messenger RNA to the intermediate and anterior lobes of the pituitary ${ }^{14.21}$ is consistent with a role for these enzymes in the biosynthesis of proopiomelanocortin-derived peptides. Characterization of proopiomelanocortin processing in the AtT20 corticotrope cell line stably transfected with a full length SPC2 cDNA lent further support for a physiological role for these enzymes in the maturation of this multivalent precursor ${ }^{39}$ Recently, recombinant SPC3 has been shown to cleave various proprotein precursors at single and paired basic amino acid processing sites in vitro. ${ }^{40.41}$ Thus, it is likely that expression of SPC2 and/or SPC 3 transcripts in neuronal cells indicates these cells have, albeit not necessarily exclusively, a peptidergic phenotype. 

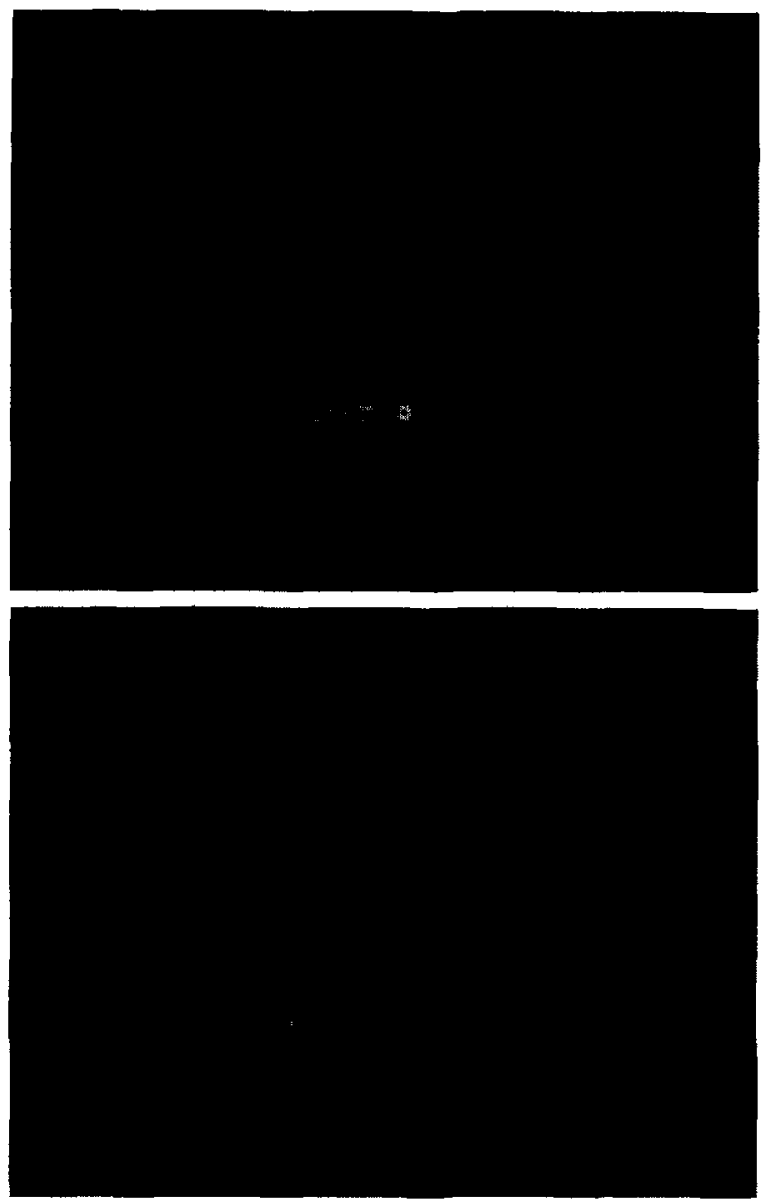

Fig. 6 Dark field photomicrographs of SPC3-specific oligonucleotide labelling of the subfornical organ following a chronic hyperosmotic stimulus. Levels of SPC3 transcripts in a control animal (A) and an animal which has been given $2 \%$ saline to drink for 7 days (B). Salt loading resulted in a large increase in SPC3 transcripts in the subfornical organ (SFO).

Neuropeptides have been mapped to all major brain areas using radioimmunoassays and immunocytochemical techniques. ${ }^{42}$ Therefore, the broad distribution of SPC2 transcripts in rat brain would be consistent with a role for this endoprotease in processing many neuropeptide precursors. Brain regions where the expression of SPC2 and SPC3 transcripts overlap may indicate differing single, paired or tetra basic residue site specificities for each enzyme within the same precursor. Alternatively, two or more neuropeptide precursors may be co-expressed in particular nerve cells, with each enzyme specific for an individual peptide precursor. Both SPC2 and SPC3 may also be involved in the cleavage of non-peptidergic proprotein precursors.
Interestingly, all of the candidate prohormone processing enzymes contain paired and tetra basic amino acid sites, some of which are known to be cleaved. ${ }^{41.43-45}$

We undertook a more detailed study of the distribution and regulation of SPC2 and SPC3 messenger RNA in the hypothalamus. The hypothalamo-neurohypophyseal system was chosen as it is the most well studied mammalian neurosecretory system. In the paraventricular nucleus SPC 3 transcripts were expressed principally in the lateral magnocellular neurons whereas SPC.2 messenger RNA was more uniformly distributed across the whole nucleus. The magnocellular cells of the supraoptic nucleus were strongly labelled with both SPC2- and SPC3-specific probes. Magnocellular neurons in the supraoptic nucleus and paraventricular nucleus synthesize neuropeptides which are released from terminals which project to the posterior pituitary. The major peptides synthesized by these cells are oxytocin and vasopressin which suggested that SPC2 and SPC 3 may be capable of processing the prooxytocin and/or provasopressin precursors. However, several other neuropeptides are coexpressed in magnocellular neurons including galanin, dynorphin, leucine enkephalin, PHI, cholecystokinin, and corticotropin releasing factor, ${ }^{46}$ albeit at significantly lower levels. At the level of the hypothalamic suprachiasmatic nucleus, SPC2 transcripts had a distribution similar to that described for vasoactive intestinal peptide immunoreactivity ${ }^{47}$ implicating provasoactive intestinal peptide as another potential substrate for this endoprotease. In contrast, the pattern of SPC3-specific labelling in this nucleus was very similar to the distribution of vasopressin immunoreactivity. ${ }^{48}$

We extended our studies in the hypothalamus with a semi-quantitative analysis of SPC2 and SPC 3 message levels following chronic salt loading of rats. Chronic ingestion of saline results in an increase in plasma osmolality and is a relatively specific stimulus for hypothalamic magnocellular neurons. ${ }^{49,50}$ The adaptive response of magnocellular neurons to chronic salt loading is increased transcription of vasopressin and oxytocin mRNA to replace depleted stores of these peptides which are secreted into the bloodstream. ${ }^{51}$ Levels of enzymes involved in the biosynthesis of vasopressin 


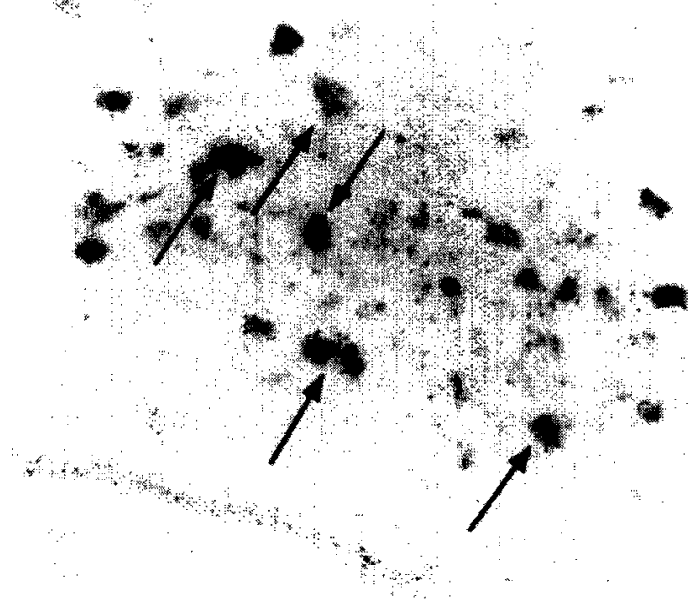

$+2$
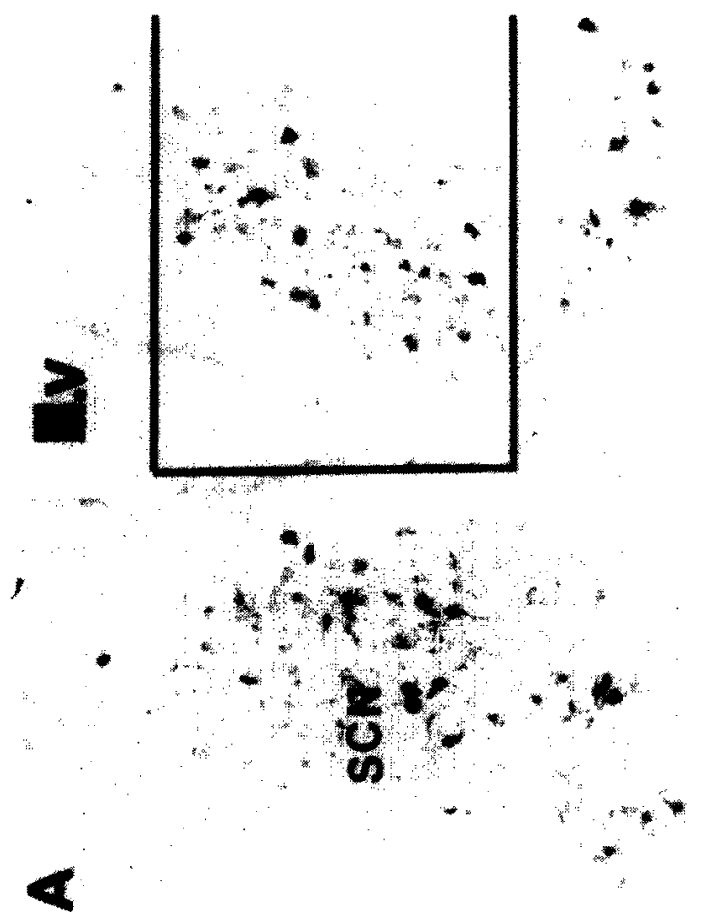
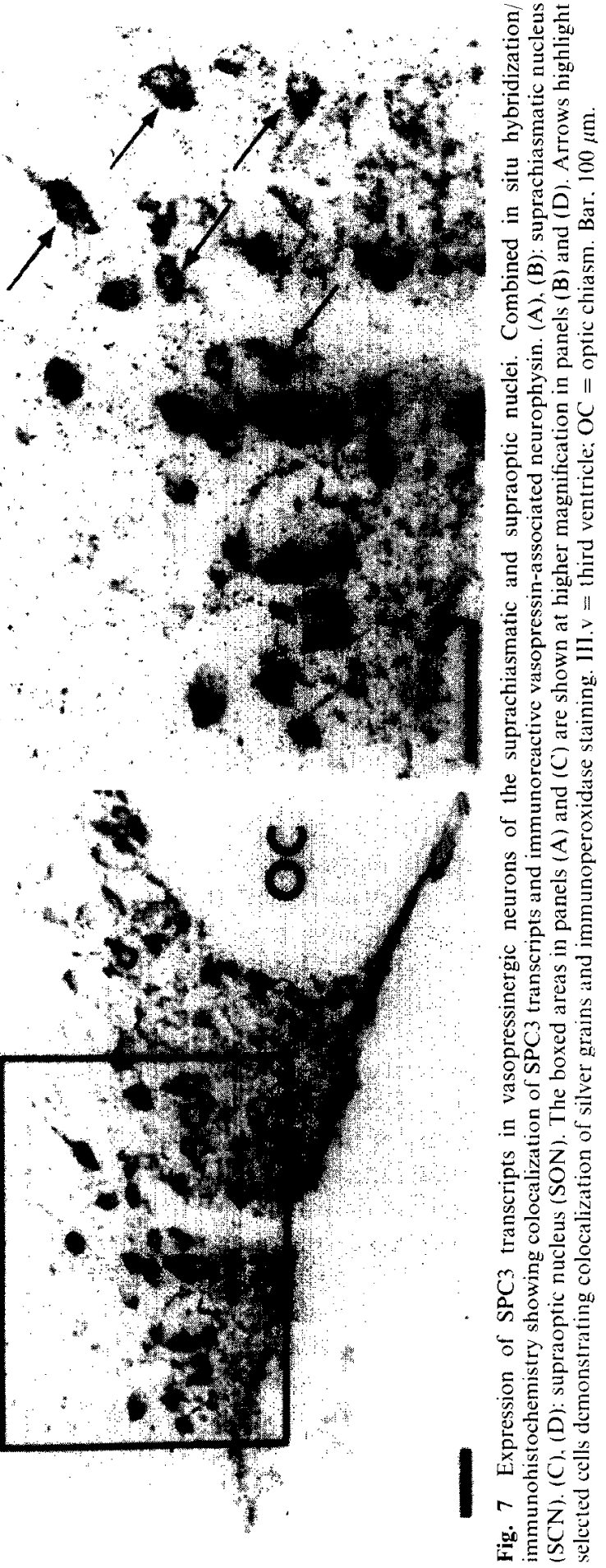

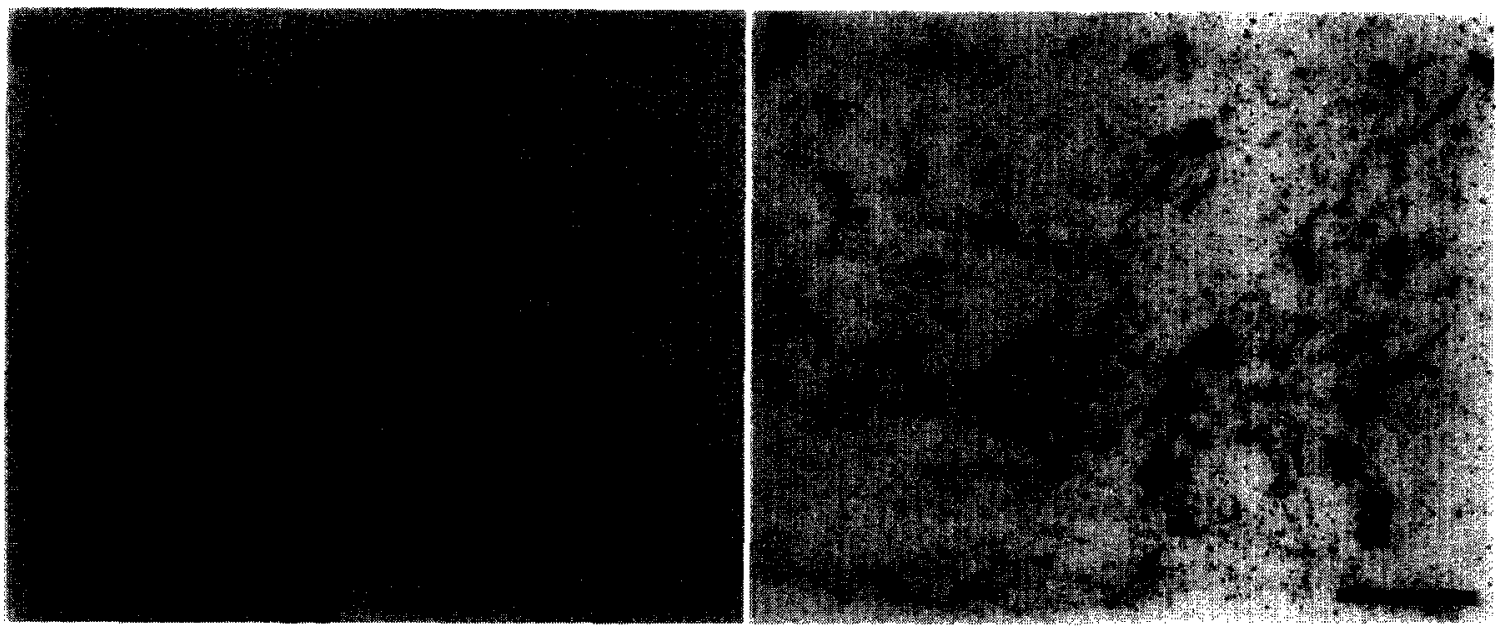

Fig. 8 Expression of SPC2 transcripts in vasopressinergic neurons of the supraoptic nucleus. Combined in situ hybridization/immunohistochemistry showing colocalization of SPC2 transcripts and immunoreactive vasopressin-associated neurophysin in magnocellular cells of the supraoptic nucleus at lower (A) and higher (B) magnifications. Arrows highlight selected cells demonstrating colocalization of silver grains and immunoperoxidase staining. $\mathrm{OC}=$ optic chiasm. Bar, $100 \mu \mathrm{m}$.

and oxytocin may also be increased. Several studies have examined the regulation of carboxypeptidase $\mathrm{H}$ and peptidyl $\alpha$-amidating mono-oxygenase, which are both involved in the biosynthesis of neuroendocrine peptides. Following treatments to alter cellular peptide levels, peptidyl $\alpha$-amidating monooxygenase messenger RNA has been shown to be coordinately regulated with proopiomelanocortin, a potential prohormone substrate, ${ }^{52}$ while conflicting results have been reported for carboxypeptidase $\mathrm{H}^{53-55}$ Quantitative in situ hybridization analysis of carboxypeptidase $\mathrm{H}$ messenger RNA levels in the rat hypothalamus following chronic salt loading resulted in increased levels of carboxypeptidase transcripts. ${ }^{56}$ In the case of members of the Kex2/subtilisin-like serine protease family, messenger RNA levels for SPC2 and SPC3, but not furin are coordinately regulated with proopiomelanocortin in the intermediate lobe of the pituitary following treatment with a dopamine agonist or antagonist. ${ }^{21,25,57}$ These data provided further indirect evidence of a role for these endoproteases in the biosynthesis of proopiomelanocortin-derived peptides. Based on the expression of SPC2 and SPC 3 in magnocellular neurons of the hypothalamus we sought to investigate a role for these enzymes in the maturation of other neuroendocrine precursors. Our studies clearly demonstrate a statistically significant rise in the levels of both SPC2 and SPC3 transcripts following chronic salt loading (Fig. 5). While no effort was made to determine copy numbers for each message, quantitation of optical density changes showed that SPC2 and SPC 3 message levels in the supraoptic nucleus showed the greatest increase following salt loading. SPC2 message levels in the paraventricular nucleus showed the smallest increases following hyperosmotic stimulation. This smaller change may be a reflection of the broader distribution of SPC2 message within the hypothalamus and its expression in cell populations not affected by a hyperosmotic stimulus. In contrast the highest levels of SPC 3 transcripts were restricted to lateral vasopressinergic magnocellular cells within the hypothalamus and these cells showed a significant increase in message levels following hyperosmotic stimulation. These data supported a role for SPC2 and SPC3 in the biosynthesis of vasopressin and/or oxytocin. The greater increases in SPC2 and SPC3 mRNA seen in the supraoptic nucleus are in agreement with the dominant response of this magnocellular cell population to $2 \%$ saline injestion. ${ }^{58}$ However, chronic salt loading of rats also leads to increases in dynorphin, galanin, corticotropin releasing factor and cholecystokinin messenger RNAs in the magnocellular cells of the supraoptic nucleus and paraventricular nucleus ${ }^{51,59-61}$ also raising them as candidate substrates for SPC2 and SPC3. SPC3 message levels also showed a significant increase in the subfornical 
organ following chronic salt loading. This is not surprising as the subfornical organ expresses several neuropeptides and is intricately involved in the regulation of water balance, containing neuroendocrine cells and terminals that link to the hypothalamoneurohypophyseal system and the control of oxytocin and vasopressin release. The large increase in SPC3 messenger RNA levels is consistent with an expected increase in activity of this organ following a hyperosmotic stimulus and a role for SPC3 in the processing of newly expressed neuropeptide precursor(s).

We further investigated the distribution of SPC2 and SPC3 transcripts in the supraoptic nucleus to determine if each enzyme was confined to either the major vasopressin or oxytocin cell subpopulations or whether both enzymes were expressed in both neuronal populations. We also examined the expression of both transcripts in the vasopressinergic subpopulation of the suprachiasmatic nucleus. Combined immunocytochemistry/in situ hybridization histochemistry demonstrated that under non-stimulated conditions SPC2 and SPC3 transcripts were seen only in the vasopressinexpressing magnocellular neurons (Fig. 7C, D; Fig. 8A, B). We cannot, of course, exclude low level expression of SPC2 and/or SPC3 in oxytocinexpressing magnocellular neurons. However, similar levels of expression of oxytocin and vasopressin peptides in the supraoptic nucleus suggests that significantly lower levels of enzyme expression in the oxytocin peptidergic subpopulation may be unlikely if these enzymes were responsible for processing the oxytocin precursor. SPC3 transcripts were also expressed in the vasopressinergic neurons of the suprachiasmatic nucleus. No SPC2 transcripts were detected in these cells indicating that the level of expression must be significantly lower than that seen for SPC3. The expression of SPC2 mRNA in the suprachiasmatic nucleus appeared to overlap with that previously reported for vasoactive intestinal peptide immunoreactivity (VIP) ${ }^{47}$ The colocalization of SPC3 with vasopressin in two hypothalamic nuclei suggests that this enzyme may be responsible for processing the provasopressin precursor, although other peptides are expressed at low levels in these cells. As SPC 3 can cleave various proproteins following pairs and single basic amino acids it may be responsible for processing rat pro- vasopressin at Lys-Arg and Arg cleavage sites to release all 3 peptide moieties contained in this peptide precursor: vasopressin, vasopressin-associated neurophysin and the 39 amino acid glycopeptide. Based on the sequences of the rat provasopressin precursor $^{62}$ and purified neurophysin-associated vasopressin, ${ }^{63}$ cleavage at the $\mathrm{C}$-terminus of the neurophysin moiety is likely to follow the $-\mathrm{Phe}^{89}$ Phe-Arg-Leu-Thr-Arg ${ }^{94}$ sequence, and the mature peptide produced by removal of the C-terminal arginine by carboxypeptidase $H$. This sequence includes a processing site motif -Arg-X-X-Arg recently identified for SPC 3. ${ }^{41,64}$ The low level expression or absence of both SPC2 and SPC 3 from oxytocin-expressing magnocellular neurons suggests that an additional member of the Kex2-related protcase family or an unrelated paired basic residue-specific endoprotease may be expressed in these cells. The apparent requirement for an additional endoprotease which mediates oxytocin biosynthesis is somewhat surprising in light of the structural similarity of the vasopressin and oxytocin proproteins. Rat vasopressin and oxytocin are 9 amino acid peptides which differ at only two residues. ${ }^{62}$ Both peptides are found at the $\mathrm{NH}_{2}$-terminus of their respective precursors and are released following proteolytic cleavage at a Lys-Arg pair. Analyses of SPC2 and SPC3 cDNAs expressed in maturation-deficient cell lines suggest that both enzymes can cleave proprotein precursors at LysArg cleavage sites. However, the important contribution of amino acids which surround paired basic residue cleavage sites towards enzyme specificity ${ }^{18.37 .39,41,64}$ may account for the apparent requirement of a prooxytocin processing enzyme unique from SPC2 or SPC3. The expression of SPC2 $\mathrm{mRNA}$ in vasopressinergic cells of the supraoptic nucleus but not the suprachiasmatic nucleus suggests it is active against alternative proprotein substrates. However, as the levels of SPC2 and SPC3 mRNA may not reflect the levels of expressed enzymes in these various cell populations, it will be important to perform immunocytochemistry at the electron microscope level to further address possible roles for these proteases in the processing of colocalized neuropeptide precursors. The differential distribution of SPC2 and SPC3 in the brain also emphasizes the need to assess colocalization of candidate enzyme(s) with candidate substrates to 
allow meaningful interpretation of substrate specificity studies performed in vitro $0^{40.41}$ or using cell line transfection approaches.

\section{Acknowledgements}

We thank H. Gainer for generously providing the vasopressinassociated neurophysin monoclonal antibody. We would also like to thank Michael J. Brownstein for his continued support and D.L. Christie and Y. Peng Loh for reading the manuscript.

\section{References}

1. Loh, Y. P., Brownstein, M. J. and Gainer, H. Proteolysis in neuropeptide processing and other neural functions. Ann. Rev. Neurosci. 1984; 7: 189-222.

2. Mains, R. E., Dickerson, I. M., May, V. el al. Cellular and molecular aspects of peptide homone biosynthesis. Frontiers in Neuroendocrinology 1990; 11: 52-89.

3. Steiner, D. F. and Oyer, P. E. The biosynthesis of insulin and a probable precursor of insulin by a human islet celi adenoma. Proc. Natl. Acad. Sci. 1967; 57: 473-480.

4. Docherty, K. and Steiner, D. F. Post translational proteolysis in polypeptide hormone biosynthesis. Annu. Rev. Physiol. 1982; 44: 625-638.

5. Loh, Y. P., Beinfeld, M. C. and Birch, N. P. In: Loh, Y. P., ed. Mechanisms of intracellular trafficking and processing of pro-proteins. Florida: CRC Press, 1993; 179-224.

6. Fuller, R. S., Sterne, R. E. and Thorner, J. Enzymes required for yeast prohormone processing. Ann. Rev. Physiol. 1988; 50: $345-362$.

7. Thomas, G. and Thorne, B. A. Gene transfer techniques to study neuropeptide processing. Ann. Rev, Physiol. 1988; 50: .323-.332.

8. Julius, D., Brake. A., Blair, L., Kunisawa, R. and Thorner $J$. Isolation of the putative structural gene for the Lys-Argcleaving endopeptidase required for processing of yeast prepro- $\alpha$-factor. Cell 1984; 37: 1075-1089.

9. Mizuno, K., Nakamura, T., Oshima, T., Tanaka, S. and Matsuo, H. Yeast KEX2 gene encodes an endopeptidase homologous to subtilisin-like serine proteases. Biochem. Biophys. Res. Commun. 1988; 156: 246-254.

10. Roebroek. A. J. M., Schalken, J. A.. Leunissen, J. A. M.. Onnekink, C., Bioemers, H. P. J, and Van de Ven, W. J. M. Evolutionary conserved close linkage of the $c$-fes/fps protooncogene and genetic sequences encoding a receptor-like protein. EMBO J. 1986; 5: 2197-2202.

11. van den Ouweland, A. M. W., van Duijnhoven, H. L. P., Keizer, G. D., Dorssers, C. J. and Van de Ven. W. J. M. Structural homology between the human fur gene product and the subtilisin-like protease encoded by yeast KEX2. Nuc. Acids Res. 1990; 18: 664.

12. Smeekens, S. P. and Steiner, D. F. Identification of a human insulinoma cDNA encoding a novel mammalian protein structurally related to the yeast dibasic processing protease Kex2. J. Biol. Chem. 1990; 265: 2997-3000.

13. Seidah. N. G., Gaspar. L., Mion. P., Marcinkiewicz, M., Mbikay, M. and Cretien. M. cDNA sequence of two distinct pituitary proteins homologous to Kex 2 and furin gene products: tissue-specific mRNAs encoding candidates for pro- hormone processing proteinases. DNA Cell Biol. 1990; 9 : 415-424.

14. Hakes, D. J., Birch, N. P., Mezey, E. and Dixon J. E. Isolation of two complementary deoxyribonucleic acid clones from a rat insulinoma cell line based on similarities to $\operatorname{Kex} 2$ and furin sequences and the specific localization of each transcript to endocrine and neuroendocrine tissues in rats. Endocrinology 1991; 129: 3053-3063.

15. Seidah, N. G., Marcinkiewicz, M., Benjannet, S. et al. Cloning and primary sequence of a mouse candidate prohormone convertase $\mathrm{PC1}$ homologous to $\mathrm{PC}$, furin. and $\mathrm{Kex} 2$ : distinct chromosomal localization and messenger RNA distribution in brain and pituitary compared to PC2. Mol. Endocrinol. 1991; 5: 111-122.

16. Smeekens, S. P., Avruch, A. S., LaMendola. J., Chan, S. J.. Steiner, D. F. Identification of a cDNA encoding a second putative prohormone convertase related to PC2 in AtT20 cells and islets of Langerhans. Proc. Nat1. Acad. Sci. 1991; 88: $340-344$.

17. Kiefer, M. C., Tucker, J. E., Joh, R., Landsberg, K. E.. Saltman, D. and Barr, P. J. Identification of a second human subtilisin-like protease gene in the fes/fps region of chromosome 15. DNA Cell Biol. 199I; 10: 757-769.

18. Nakayama, K., Hosaka, M., Hatsuzawa. K. and Murakami, $K$. Cloning and functional expression of a novel endoprotease involved in prohormone processing at dibasic sites. J. Biochem. 1991; 109: 803-806.

19. Nakayama, K., Kim. W.-S., Torii S. et al. Identification of the fourth member of the mammaliam endoprotease family homologous to the yeast Kex2 protease. J. Biol. Chem. 1992; 267: $5897-5900$.

20. Chan, S. J., Oliva Jr, A. A.. LaMendola, J.. Grens, A., Bode, H. and Steiner, D. F. Conservation of the prohormone convertase gene family in metazoa: analysis of cDNAs encoding a PC3-like protein from hydra. Proc. Natl. Acad. Sci. USA 1992: 89: 6678-6682.

21. Day, R., Schafer, M. K.-H., Watson, S. J., Chretien, M. and Seidah. N. G. Distribution and regulation of the prohormone convertases $\mathrm{PC} 1$ and $\mathrm{PC} 2$ in the rat pituitary. Mol. Endocrinol. 1992; 6: 485-497.

22. Young. W. S. III, Mezey, E. and Siegel, R. Vasopressin and oxytocin mRNAs in adrenalectomized and Brattleboro rats: Analysis by quantitative in situ hybridization histochemistry. Mol. Brain Res. 1986; 1: 231-241.

23. Birch. N. P., Rodriguez, C., Dixon, J. E. and Mezey E. Distribution of carboxypeptidase $H$ messenger RNA in rat brain using in situ hybridization histochemistry: implications for neuropeptide biosynthesis. Mol. Brain Res. 1990; 7: 53-59.

24. Ben-Barak, Y., Russell, J., Whitnall, M., Ozato, K. and Gainer, H. Neurophysin in the hypothalamo-neurohypophysial system. 1. Production and characterization of monoclonal antibodies. J. Neuroscience 1985; 5: 81-97.

25. Birch. N. P.. Tracer, H., L., Hakes, D. J. and Loh, Y. P. Coordinate regulation of mRNA levels of pro-opiomelanocortin and the candidate processing enzymes $\mathrm{PC} 2$ and PC 3, but not furin. in rat pituitary intermediate lobe. Biochem. Biophys. Res. Commun. 1991; 179: 1311-1319.

26. Schafer, M. K.-H., Day, R., Cullinan. W. E.. Chretien, M., Seidah, N. G. and Watson, S. J. Gene expression of prohormone and proprotein convertases in the rat CNS: a comparative in situ hybridization analysis. J. Neuroscience 1993; 13: 1258-1279.

27. Vilijn, M.-H., Das, B., Kessler, J. A. and Fricker, L. D. Cultured astrocytes and neurons synthesize and secrete Car- 
boxypeptidase E, a neuropeptide processing enzyme. J. Neurochem. 1989; 53: 1487-1493.

28. MacCumber, M. W., Snyder, S. H. and Ross. C. A. Carboxypeptidase $\mathrm{E}$ (enkephalin convertase): mRNA distribution in rat brain by in situ hybridization. $\mathbf{J}$. Neurosci. 1990; 10: 2850-2860.

29. Chung, K. and Lee, W. T. Vasoactive intestinal polypeptide (VIP) immunoreactivity in the ependymal cells of the rat spinal cord. Neuroscience $1988 ; 95: 1-6$.

30. Stornetta. R. L., Hawelu-Johnson, O. L., Guyenet, P. G. and Lynch, K. R. Astrocytes synthesize angiotensinogen in brain. Science 1988; 242: 1444-1446.

31. Vilijn. M. H., Vaysse, P. J. J., Zukin, R. S. and Kessler, J. A. Expression of proenkephalin mRNA by cultured astrocytes and neurons. Proc. Natl. Acad. Sci. USA 1988; 85: 655I6555 .

32. Shinoda. H., Marini, A. M.. Cosi, C. and Schwartz, J. P Brain region and gene specificity of neuropeptide gene expression in cultured astrocytes. Science 1989; 245: 415417

33. Melner. M. H., Low. K. Cò., Allen, R. G., Nielsen, O. P., Young, S. L. and Saneto, R. P. The regulation of proenkephalin expression in a distinct population of glial cells. EMBO J. 1990; 9: 791-796.

34. Spruce, B. A., Curtis, R., Wilkin, G. P. and Glover, D. M. A neuropeptide precursor in cerebellum: proenkephalin exists in subpopulations of both neurons and astrocytes. EMBO J. 1990: 9: 1787-1795.

35. Korner, J., Chun, J., Harter, D. and Axel, R. Isolation and functional expression of a mammalian prohormone processing enzyme, murine prohormone convertase 1. Proc. Natl. Acad. Sci. USA 1991; 88: 6834-6838.

36. Shennan, K. J., Smeekens, S. P., Steiner, D. F. and Docherty, K. Characterization of PC2, a mammalian Kex 2 hom ologue, following expression of the cDNA in micrinjected Xenopus oocytes. FEBS Lett. 1991; 284: 277-280.

37. Thomas, L., Leduc, R., Thorne, B. A., Smeekens, S. P., Steiner, D. F. and Thomas G. Kex2-like endoproteases PC2 and $\mathrm{PC} 3$ accurately cleave a model prohormone in mammalian cells: evidence for a common core of neuroendocrine processing enzymes. Proc. Natl. Acad. Sci. USA 1991: 88 : $5297-5301$.

38. Benjannet, S., Rondeau, N., Day, R., Chretien, M. and Seidah, N. G. PC1 and $\mathrm{PC} 2$ are proprotein convertases capable of cleaving proopiomelanocortin at distinct pairs of basic residues. Proc. Natl. Acad. Sci. USA 1991: 88: 3564 3568.

39. Zhou, A., Bloomquist, B. T. and Mains, R. The prohormone convertases $\mathrm{PCI}$ and $\mathrm{PC} 2$ mediate distinct endoproteolytic cleavages in a strict temporal order during proopiomelanocortin biosynthetic processing. J. Biol. Chem. 1993; 268: 1763-1769

40. Zhou. Y. and Lindberg, I. Purification and characterization of the prohormone convertase PC1 (PC3). J. Biol. Chem. 1993: 268: 5615-5623.

41. Rufaut, N. W., Brennan, S. O., Hakes, D. J., Dixon, J. E. and Birch N. P. Purification and characterization of the candidate prohormone processing enzyme SPC3 produced in a mouse cell line. J. Biol. Chem. 1993; 268: 20291-20298.

42. Palkovits, M. Neuropeptides in the brain. In: Martin, L. and Ganong, W. F., eds. Frontiers in Neuroendocrinology 10. New York: Raven Press, 1988: 1-44.

43. Christie, D. L.. Batchelor, D. C. and Palmer, D. J. Identification of kex2-related proteases in chromaffin granules by partial amino acid sequence analysis J. Biol. Chem. 1991: 266: $15679-15683$.
44. Eipper, B. A., Milgram, S. L., Husten, E. J., Yun, H. Y. and Mains, R. E. Peptidylglycine $\alpha$-monooxygenase: a multifunctional protein with catalytic, processing and routing domains. Protein Science 1993: 2: 489-497.

45. Leduc, R., Molloy, S. S., Thorne, B. A. and Thomas, G. Activation of human furin precursor processing endoprotease occurs by an intramolecular autoproteolytic cleavage. J. Biol. Chem. 1992; 267: 14304-14308.

46. Brownstein, M. J. and Mezey, E. Multiple chemical messengers in hypothalamic magnocellular neurons. Prog. Brain Res. 1986: 68: 161-168

47. Sims, K. B., Hoffman, S. I. S. and Zimmerman, E. A. Vasoactive intestinal polypeptide (VIP) in mouse and rat brain: an immunocytochemical study. Brain Res. 1980; 186: $165-183$

48. Vandesande, F., Dierickx, K. and De May, J. Identification of the vasopressin-neurophysin producing neurons of the rat suprachiasmatic nuclei. Cell Tissue Res. 1975: 156: 377 380

49. Burbach. J. P. H., De Hoop. M. J., Schmale H. et al. Differential responses to osmotic stress of vasopressinneurophysin mRNA in hypothalamic nuclei. Neuroendocrinology $1984 ; 39: 582-584$.

50. Sherman. T. G., McKelvey, J. F. and Watson, S. J. Vasopressin mRNA regulation in individual hypothalamic nuclei: a northern and in situ hybridization analysis. $J$. Neurosci. 1986; 6: 1685-1694.

51. Lightman, S. L. and Young, W. S. III. Vasopressin, oxytocin, dynorphin. enkephalin and corticotropin-releasing factor mRNA stimulation in the rat. J. Physiol. 1987; 394: $22 \cdots 39$.

52. Thiele, E. A.. Marek, K. L. and Eipper, B. A. Tissue-specific regulation of peptidylglycine $\alpha$-amidating monooxygenase expression. Endocrinology 1989; 125: 2279-2288.

53. Mains, R. E. and Eipper, B. A. Secretion and regulation of two biosynthetic enzyme activities, peptidyl-glycine $\alpha$ amidating monooxygenase and a carboxypeptidase, by Inouse pituilary corticotropic tumor cells. Endocrinology 1984: 115: 1683-1690.

54. Thiele, E. A. and Fricker, L. D. Regulation of carboxypeptidase E in AIT-20/DI6v cells. In: Imura. H., ed. Progress in Endocrinology. Amsterdam: Elsevier, 1988: 329-335.

55. Rodriguez, C., Brayton, K. A., Brownstein, M. and Dixon. J. E. Rat carboxypeptidase $\mathrm{H}$ : cloning, characterization and sequence of the cDNA and regulation of the mRNA by corticotropin releasing factor, J. Biol. Chem. 264: 59885995.

56. Bondy, C. A., Whitnall, M. H. and Brady, L. S. Regulation of carboxypeptidase $\mathrm{H}$ gesı expression in magnocellular neurons: response to osmotic stimulation. Mol. Endocrinol. 1989: 3: 2086-2092.

57. Bloomquist, B. T., Lipper, B. A. and Mairs, R. E. Prohormone-converting enzymes: regulation and evaluation of function using antisense RNA. Mol. Endocrinol. 1991; 5: 2014-2024

58. Murray, M. Effects of dehydration on incorporating of $3 \mathrm{H}$ tyrosine by some hypothalamic neurons in rat. Exp. Neurol. $1967 ; 19: 212231$

59. Young, W. S. III. Corticotropin-releasing factor mRNA in the hypothalamus is affected differently by drinking saline and dehydration. FEBS Lett. 1986; 208: 158-162.

60. Sherman. T. G., Day, R., Civelli, O. et al. Regulation of hypothalamic magnocellular neuropeptides and their $m$ RNAs in the Brattleboro rat: coordinate responses to further osmotic challenge. J. Neurosci. 1988; 8: 3785-3796. 
61. Meister, B., Cortes, R., Villar, M. J. and Hokfelt T. Increase of galanim mRNA and decrease of galanin immunoreactivity in magnocellular neurons of the hypothalamic supraoptic and paraventricular nuclei. Eur. J. Neurosci. 1989; Suppl.2: 127.

62. Ivell, R. and Richter, D. Structure and comparison of the oxytocin and vasopressin genes from rat. Proc. Natl. Acad. Sci. USA 1984; 81: 2006-2010.

63. Chauvet, M.-T., Chauvet, J. and Acher, R. Identification of rat neurophysins: complete amino acid sequences of MSEL- and VLDV-neurophysins. Biochem. Biophys. Res. Commun. 1981; 103: 595-603.

64. Nakayama, K., Watanabe, T., Nakagawa, T. et al. Consensus sequence for precursor processing at mono-arginyl sites: evidence for the involvement of a Kex2-like endoprotease in precursor cleavages at both dibasic and monoarginyl sites. J. Biol. Chem. 1992; 267: 16335-16340. 